\title{
Psychometric properties of the external Housing-Related Control Belief Questionnaire among people with Parkinson's disease
}

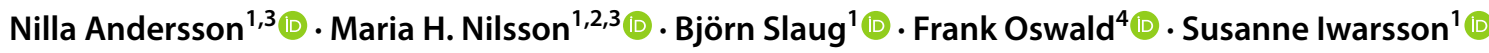

Received: 3 October 2019 / Accepted: 10 January 2020 / Published online: 7 February 2020

(c) The Author(s) 2020

\begin{abstract}
Background Housing-related control beliefs are associated with aspects of health among older people in general. Research on Parkinson's disease (PD) focusing on perceptions of the home are rare and instruments capturing perceived aspects of home have seldom been used.

Aims To evaluate psychometric properties of the external Housing-related Control Beliefs Questionnaire (HCQ) among people with PD.

Methods The external HCQ were administrated to 245 participants with PD, (mean age $=69.9$ years; mean PD duration $=9.7$ years). External HCQ has 16-items, with five response options. The psychometric properties evaluated were data quality, structural validity (factor analysis), floor and ceiling effects, corrected item total correlations, internal consistency and construct validity (testing correlations with relevant constructs according to pre-defined hypotheses).

Results Data quality was high. Structural validity showed a unidimensional construct with removal of two items. Homogeneity was questionable, but strengthened after the removal of the two items. For the 14-item version internal consistency was $\alpha=0.78$ and SEM 4.47. Corrected item total correlation ranged between 0.31 and 0.54 and no floor or ceiling effects. Significant correlations with relevant constructs supported the construct validity.

Conclusions Taken together, the psychometric results suggest a 14-item version of the external HCQ to be sufficiently reliable and valid for use in the PD population. The results pave the way for further studies, using the HCQ to analyse how perceptions of control of the home may be associated with health among people ageing with PD.
\end{abstract}

Keywords Psychometrics $\cdot$ Control beliefs $\cdot$ Parkinson's disease $\cdot$ Reliability $\cdot$ Validity

\section{Introduction}

A basic methodological prerequisite is that the data collection instruments are evaluated psychometrically in the targeted populations. In this study, we evaluated the external Housing-related control beliefs Questionnaire (external

Nilla Andersson

nilla.andersson@med.lu.se

1 Department of Health Sciences, Lund University, Lund, Sweden

2 Clinical Memory Research Unit, Department of Clinical Sciences Malmö, Lund University, Lund, Sweden

3 Memory Clinic, Skåne University Hospital, Malmö, Sweden

4 Interdisciplinary Ageing Research, Goethe University, Frankfurt, Germany
HCQ) [1-4] for use among people with Parkinson's disease (PD).

The transaction between a person and his/her immediate home environment is dynamic, comprising of both objective environmental and perceived aspects of housing [5]. One perceived aspect of importance for maintenance of independence and autonomy [6] in old age is control beliefs. This is related to the concept locus of control [7] and has been regarded in relation to different outcomes such as cognitive functioning, daily independence and housing [1-4, 8]

Housing-related control beliefs address how people think about how they can deal with daily issues within their immediate home environment. Examining agerelated differences and changes in housing-related control beliefs can improve the understanding of the mechanisms underlying the achievement and maintenance of autonomy and well-being in old age in general [4] and in particular with respect to changing autonomy $[1,3]$. Oswald and 
colleagues developed an instrument to capture the concept that is the external HCQ Questionnaire [4]. The external HCQ instrument was introduced and psychometrically evaluated in two studies with community-dwelling older adults (sample 1, $N=485,66-69$ years; sample 2, $N=107$; 65-91 years) [4]. In this evaluation, (internal consistency and test-retest reliability) the external HCQ instrument had two sub-scales, "powerful others" (sample 1: $\alpha=0.66$; sample 2: $\alpha=0.72, r_{\mathrm{tt}}=0.78$ ), and "chance" (sample 1: $\alpha=0.83$; sample 2: $\alpha=0.76, r_{\mathrm{tt}}=0.50$ ). The two sub-scales were also found to correlate with higher age, lower education, and lower income [4]. The 16 items of the two sub-scales were later combined, with results suggesting sufficient internal consistency $(\alpha=0.72)$ [1]. Later studies have indicated associations between the external HCQ and ADL, life satisfactions, depression and psychological well-being [1, 9-11].

PD is a chronic neurodegenerative disease, with symptoms that worsen over time and with increasing complexity [12]. It often results in ADL difficulties, even at an early stage of the disease [13]. For example, up to $75 \%$ have gait and balance problems, complex activities such as home maintenance and shopping are more difficult to perform for people with PD than for compared controls [13]. There seems to be a shift from internal to external locus of control [7] for this group, as a strategy to manage a sense of lost control with the unpredictable and progressive disease [14]. When it comes to housing conditions, people with PD more often move to assisted living facilities $[12,15]$ and at an earlier age compared to the population in general [15]. This has a great impact for people living with PD including their families, and implies high societal costs [12]. To the best of our knowledge only two studies have used the external HCQ instrument in PD samples [16, 17]. Comparing housing aspects between people with self-reported PD $(N=20)$ and matched controls $(N=60)$, Nilsson et al. found no significant difference concerning external HCQ [16]. Further, they explored associations between aspects of health and perceived housing and found that people with PD rely on external control in relation to housing [17], which are in line with studies among community-dwelling older people [1]. Since, psychometric properties are sample dependent [18] and the external HCQ instrument has not been evaluated among people with PD it is uncertain how valid these results are.

Therefore, the aim of this study was to examine the psychometric properties of the external HCQ instrument to identify whether it validly and reliably capture external housing-related control beliefs among people with PD. We examined data quality, structural validity, floor and ceiling effects, corrected item total correlations, internal consistency reliability, convergent validity and known group validity.

\section{Methods}

\section{Participants and recruitment}

We used baseline data collected for the longitudinal cohort study "Home and Health in People Ageing with Parkinson's Disease" (HHPD) in 2013. The design and procedures of the HHPD were described in detail in a study protocol [19]. Participants were recruited from three hospitals in Skåne County (i.e., study district). The inclusion criterion was being diagnosed with PD (G20.9) since at least one year. The exclusion criteria were difficulties understanding or speaking Swedish, having cognitive difficulties (evaluated by a specialized PD-nurse and screening of medical records) or other reasons making the individual unable to give informed consent (i.e., hallucinations or a recent stroke) or to take part in the majority of the data collection. Out of 653 possible participants, 58 lived outside the study district and were not included. Further, 158 were excluded having difficulties understanding or speaking Swedish $(n=10)$; severe cognitive problems $(n=91)$ or other reasons that made them unable to give informed consent or take part in the majority of the data collection (e.g. hallucinations, recent stroke) $(n=57)$. The remaining 437 potential participants were invited to participate. However, 22 of those were unreachable and two had their diagnosis changed. Furthermore, 157 out of 413 remaining participants declined and one had extensive missing data $(n=255)$. For this study, another eight persons were excluded due to comprehensive missing data on core variables and two more were excluded as they lived in residential care units. Thus, the final study sample was $N=245$ (60.8\% men; mean age $=69.9$ years; $\min -\max =45-93$ years) and the median duration with PD was 8 years ( $\mathrm{q} 1-\mathrm{q} 3=5-13$ ) (Table 1 ). Additional descriptive data was collected, which is presented and described as footnotes in Table 1, capturing, i.e. cognitive [20], motor functioning [21] and housing variables.

Written informed consent was obtained from each participant and the study was conducted in accordance with the Helsinki Declaration. The Regional Ethical Review Board in Lund (No. 2012/558) approved the HHPD.

\section{Data collection}

Two project administrators underwent project-specific training and completed the data collection. Data was collected through phone interview, postal survey and a subsequent home visits. The external HCQ instrument was administrated at the home visit. 
Table 1 Sample characteristics, $N=245$

\begin{tabular}{|c|c|c|}
\hline Variable, $n(\%)$ unless otherwise stated & Descriptive & Missing, $n$ \\
\hline \multicolumn{3}{|l|}{ Participant characteristics } \\
\hline \multicolumn{3}{|l|}{ Sex } \\
\hline Women/men & $96(39.2) / 149(60.8)$ & 0 \\
\hline Age, mean (SD) & $69.7(9.0)$ & 1 \\
\hline Parkinson's duration years, median (q1-q3) & $8(5-13)$ & 1 \\
\hline \multicolumn{3}{|l|}{ Disease severity ( $\mathrm{HY}^{\mathrm{a}}$ in on) } \\
\hline HY I & $50(20.4)$ & 0 \\
\hline HY II & $73(29.8)$ & 0 \\
\hline HY III & $62(25.3)$ & 0 \\
\hline HY IV & $54(22)$ & 0 \\
\hline HY V & $6(2.5)$ & 0 \\
\hline Motor symptoms (UPDRS ${ }^{b}$ III), median (q1-q3) & $29(22-39)$ & 4 \\
\hline Cognitive function (MOCA) ${ }^{\mathrm{c}}$, median (q1-q3) & $26(23-28)$ & 5 \\
\hline $\mathrm{ADL}^{\mathrm{d}}$ (ADL Staircase), median (q1-q3) & $4(0-8)$ & 0 \\
\hline Higher education (university), yes/no & $83(33.9) / 162(66.1)$ & 0 \\
\hline Life satisfaction (Lisat $-11,1$ item), median ( $\mathrm{q} 1-\mathrm{q} 3$ ) & $5,(4-5)$ & 0 \\
\hline \multicolumn{3}{|l|}{ Housing characteristics } \\
\hline \multicolumn{3}{|l|}{ Type of housing } \\
\hline Apartment & $109(44.5)$ & 0 \\
\hline Housing & $131(53.5)$ & 0 \\
\hline Other & $5(2)$ & 0 \\
\hline \multicolumn{3}{|l|}{ Residential location } \\
\hline Rural & $79(32.2)$ & 0 \\
\hline Semi-Urban & $65(26.5)$ & 0 \\
\hline Urban & $101(41.3)$ & 0 \\
\hline \multicolumn{3}{|l|}{ Tenure of housing } \\
\hline Privately owned/rental & $184(75.1) / 61(24.9)$ & 0 \\
\hline Accessibility problems (HE) ${ }^{\mathrm{e}}$, median (q1-q3) & $185(95-272)$ & 1 \\
\hline Housing adaptation, yes/no & $80(32.7) / 165(67.3)$ & 0 \\
\hline Years in present dwelling, median (q1-q3) & $17(5-35)$ & 0 \\
\hline
\end{tabular}

${ }^{\text {a } H o e h n ~ a n d ~ Y a h r, ~ e l i g i b l e ~ s c o r e s ~ 1-5 ~}$

${ }^{\mathrm{b}}$ Unified Parkinson's disease rating scale, eligible scores $=0-108$

${ }^{\mathrm{c}}$ Montreal cognitive assessment, 0-30

${ }^{\mathrm{d}}$ Activities of daily living, eligible scores $0-27.9$ items that are rated from $0-3 \quad(0=$ independent $-3=$ dependent) and summed to a total sum score. Higher scores $=$ the more dependent

${ }^{\mathrm{e}}$ Housing Enabler, eligible scores 0-1844

\section{Measures}

\section{External Housing-related control beliefs (HCQ) instrument}

The external HCQ instrument captures external control beliefs in relation to the home, such as help from others or chance/luck affecting the perceived control [1-4]. It is interview-administered and comprises of 16 items, each with five response options $(1=$ strongly disagree, $5=$ strongly agree) [3]. The sum score ranges from 16 to 80 points (higher scores $=$ indicate lower perceived control) $[1,2]$. A multi-lingual research team engaged in an iterative translation process, which resulted in the Swedish version of the instrument used in the present study.

\section{Construct validity hypotheses and variables used}

Based on previous research [1,22] and clinical reasoning, convergent and known group validity were assessed using predefined hypotheses (see Table 3, left column), including four variables identified as relevant: Disease severity was assessed according to the five-stage Hoehn and Yahr (HY) scale [23] in the "on-state" (range I-V, higher $=$ worse). 
Housing accessibility was assessed with the Housing Enabler (HE) instrument [24], administrated in three steps. The first step consists of dichotomous assessments of functional limitations and dependence on mobility devices and the second step is dichotomous assessments of physical environmental barriers. In a third step combining data from previous steps, a matrix-generated score is computed. A higher score indicates greater accessibility problems ( $\max$ score $=1,844$ ) [24].

ADL dependence was evaluated through interviews using the ADL Staircase $[25,26]$, which consists of nine items divided into personal ADL (P-ADL; feeding, transfer, toileting, dressing and bathing) and instrumental ADL (I-ADL; cooking, transportation, shopping and cleaning). Each assessment was rated on a three-graded scale: independent/ partly dependent/dependent. If rated as independent, the participants was asked to state if the activity was done with or without difficulties [27]. A total sum score of the ADL Staircase was used (range 0-27), the higher the scores the more dependent.

The self-administrated General Self-Efficacy Scale [28] instrument consists of 10 items; each with four response options (ranging from "not at all true" to "exactly true"). The total sum score range from 10 to 40 points; the higher scores-the greater self-efficacy. The scale has been psychometrically evaluated among people with $\mathrm{PD}$, with satisfactory results [29].

\section{Data analysis and statistical analysis}

Participant characteristics were described using median, quartiles and frequencies, and psychometric properties were evaluated as described below.

Data quality was calculated for each item/total scale, i.e. the percentage of missing data for items and total scores [18], without imputation. Structural validity was investigated with exploratory factor analysis. Because the data was ordinal and not normally distributed, we used a principal axis factoring. Visual examinations of the scree plot and the factor loadings were used to evaluate the number of factors to include in the model [30]. Floor and ceiling effects were calculated for the total score [31] using the recommended 15-20\% upper limit for interpretation of the results [18]. The distribution of response alternatives was examined to detect floor and ceiling effects on item level. While seemingly high, for interpretation we used $75 \%$ limit, which to the best of our knowledge is the only published recommendation available [32]. Internal consistency reliability was evaluated with Cronbach's alpha, using values $>0.70$ as acceptable [18]. The standard error of measurement (SEM) was calculated and complemented with a 95\% confidence interval [18]. Corrected item-total correlation was investigated, considering values $>0.3$ to indicate the correctness of summing the items to a total score [18]. To examine whether the items evaluate the same underlying construct, correlations $>0.4$ were considered [18]. Convergent and known group validity were analysed with Spearman's rang correlation and Mann-Whitney $U$ test, respectively [33]. The level of statistical significance was set to $p<0.05$.

The IBM SPSS statistics 25 software (IBM Corporation, Armonk, NY, USA) and the HE software (Veten \& Skapen HB and Slaug Enabling Development, Lund and Staffanstorp, Sweden) were used for data and statistical analysis.

\section{Results \\ Data quality}

The median (q1-q3) total scores of the 16 item external HCQ instrument was $=38(32-47)$. The overall data quality was high, with low proportions of missing item responses: $0.4 \%$ for two items and $0.8 \%$ for one (Table 2).

\section{Structural validity}

The scree plot indicated that there were few factors. Using the criteria mentioned in the method section (testing one, two and three factor solutions), the results showed that the one-factor solutions was the best fit, explaining $19.8 \%$ of the variance. Due to the uni-dimensionality of the construct, rotation was not possible. The items "Whether or not I can stay in my home depends on luck and circumstance" and "Where and how I live has happened by chance", had low corrected item correlations $(<0.3)$ and low factor loadings $(<0.32)$ [34]. Analysis excluding these items resulted in a one-factor solution with similar results for the remaining 14 items, explaining $21.4 \%$ of the variance.

\section{Floor and ceiling effects}

Concerning the total score, no floor $(0.4 \%)$ or ceiling effects were found $(0 \%)$. On item level, there was tendency to floor effect for some. For details, see Table 2.

\section{Corrected item total correlations}

The corrected item total correlations varied between $0.24-0.56$. Five items had values over 0.4 and 2 items had values $<0.3$. Two items (Table 2 ) with values $<0.3$ were removed, resulting in improved corrected item total correlations. In the 14 -item version, all 14 items were $>0.3$ and five $>0.4$. 
Table 2 Results of psychometric analyses for the 16- and 14-item versions of the external HCQ instrument, $N=245$

\begin{tabular}{|c|c|c|c|c|c|c|}
\hline \multirow[t]{3}{*}{ External HCQ ${ }^{\mathrm{a}}$ instrument item } & \multirow[t]{3}{*}{ Median (q1-q3) } & \multirow[t]{3}{*}{ Missing $(n)$} & \multirow{2}{*}{$\begin{array}{l}\text { Floor effect, } n(\%) \\
\text { Response options }\end{array}$} & \multirow[t]{2}{*}{ Ceiling effect, $n(\%)$} & \multicolumn{2}{|c|}{$\begin{array}{l}\text { Corrected item-total correla- } \\
\text { tion }\end{array}$} \\
\hline & & & & & \multirow[t]{2}{*}{16 items } & \multirow[t]{2}{*}{14 items } \\
\hline & & & "Strongly disagree" & "Strongly agree" & & \\
\hline $\begin{array}{l}\text { I rely on others for helpful } \\
\text { improvement in my home }\end{array}$ & $3(1-4)$ & 0 & $68(27.8)$ & $16(6.5)$ & 0.35 & 0.34 \\
\hline $\begin{array}{l}\text { Having a nice place is luck. You } \\
\text { cannot influence it }\end{array}$ & $2(1-3)$ & 0 & $109(44.5)$ & $14(5.7)$ & 0.45 & 0.45 \\
\hline $\begin{array}{l}\text { Whether I will stay in my home, } \\
\text { depend on other people }\end{array}$ & $3(2-4)$ & 0 & $46(18.8)$ & $20(8.2)$ & 0.39 & 0.36 \\
\hline $\begin{array}{l}\text { It's luck if my neighbours will } \\
\text { step in, if I need help }\end{array}$ & $2(1-3)$ & 0 & $87(35.5)$ & $13(5.3)$ & 0.39 & 0.38 \\
\hline $\begin{array}{l}\text { To do anything interesting outside } \\
\text { my home, I rely on others }\end{array}$ & $2(1-4)$ & 0 & $109(44.5)$ & $30(12.2)$ & 0.48 & 0.50 \\
\hline $\begin{array}{l}\text { Whether or not I can stay in my } \\
\text { home depends on luck and } \\
\text { circumstance }^{c}\end{array}$ & $4(4-5)$ & 0 & $21(8.6)$ & $114(46.5)$ & 0.24 & - \\
\hline $\begin{array}{l}\text { I rely on others, to use the sup- } \\
\text { port services and community } \\
\text { facilities }\end{array}$ & $2(1-4)$ & 0 & $106(43.3)$ & $31(12.7)$ & 0.36 & 0.38 \\
\hline $\begin{array}{l}\text { You have to live with the way } \\
\text { your home is. You can't do } \\
\text { anything about it }\end{array}$ & $2(1-4)$ & 0 & $100(40.8)$ & $30(12.2)$ & 0.38 & 0.39 \\
\hline $\begin{array}{l}\text { When people offer to help, I can't } \\
\text { say no }\end{array}$ & $2(1-3)$ & 2 & $107(44.0)$ & $23(9.5)$ & 0.48 & 0.49 \\
\hline $\begin{array}{l}\text { Where and how I live, has hap- } \\
\text { pened by chance }{ }^{c}\end{array}$ & $3(1-5)$ & 0 & $97(39.6)$ & $70(28.6)$ & 0.27 & - \\
\hline $\begin{array}{l}\text { Others have told me how to } \\
\text { arrange the furnisher in my } \\
\text { home }\end{array}$ & $1(1-2)$ & 0 & $160(65.3)$ & $17(6.9)$ & 0.36 & 0.36 \\
\hline $\begin{array}{l}\text { It is luck if I can continue my way } \\
\text { of life, in my home in the future }\end{array}$ & $3(2-4)$ & 1 & $56(23.0)$ & $37(15.2)$ & 0.56 & 0.53 \\
\hline $\begin{array}{l}\text { I listen to advice from others, not } \\
\text { to change anything in my home }\end{array}$ & $2(1-4)$ & 1 & $94(38.5)$ & $20(8.2)$ & 0.33 & 0.32 \\
\hline $\begin{array}{c}\text { The way my home has been set } \\
\text { up, has happened by chance }\end{array}$ & $4(2-5)$ & 0 & $42(17.1)$ & $65(26.5)$ & 0.33 & 0.34 \\
\hline $\begin{array}{l}\text { Other people are to blame if my } \\
\text { home is not a place where I can } \\
\text { enjoy life }\end{array}$ & $1(1-2)$ & 0 & $180(73.5)$ & $8(3.3)$ & 0.44 & 0.45 \\
\hline $\begin{array}{l}\text { If there are support services or } \\
\text { community facilities, depends } \\
\text { on luck }\end{array}$ & $2(1-4)$ & 0 & $98(40.0)$ & $24(9.8)$ & 0.32 & 0.31 \\
\hline \multicolumn{7}{|l|}{ External HCQ, 16-item version } \\
\hline $\begin{array}{l}\text { Total sum score, median (q1- } \\
\text { q3) }\end{array}$ & $38(32-47)$ & 4 & $1(0.4)$ & $0(0.0)$ & Cronbach alpha/SEM ${ }^{\mathrm{b}}$ & \\
\hline Total mean score, mean (SD) & $2.52(0.66)$ & 4 & & & $0.78 / 4.97$ & \\
\hline \multicolumn{7}{|l|}{ External HCQ, 14-item version } \\
\hline $\begin{array}{l}\text { Total sum score, median (q1- } \\
\text { q3) }\end{array}$ & $32(26-39)$ & 4 & $2(0.8)$ & $0(0.0)$ & Cronbach alpha/SEM & \\
\hline Total mean score, mean (SD) & $2.28(0.69)$ & 4 & & & $0.78 / 4.47$ & \\
\hline
\end{tabular}

${ }^{a}$ Housing-related Control Belief Questionnaire, score range 1-5

${ }^{\mathrm{b}}$ Standard error of measurement

${ }^{\mathrm{c}}$ Item removed for the 14-item version 


\section{Internal consistency reliability}

Cronbach's alpha was 0.78 and SEM 4.97 (95\% CI, -4.73 to 14.67). For the 14-item version, Cronbach's alpha remained unchanged and SEM was 4.47 (CI 95\%, -4.29 to 13.23) (Table 2).

\section{Convergent and known group validity}

Regarding the known group validity, the group comparisons showed a significant difference between HY stages I-III and HY IV-V (Table 3). The convergent validity analysis showed that lower external HCQ correlated significantly with living in a dwelling with a lower magnitude of accessibility problems. Higher external HCQ correlated significantly with being dependent in ADL and lower general self-efficacy. Running the analysis for the 14-item version yielded roughly the same results.

\section{Discussion}

This study showed that the external HCQ instrument generates data of high quality and has acceptable internal consistency reliability with no floor and ceiling effects among people with PD. The homogeneity is questionable due to somewhat low corrected item total values, but improved after the removal of two items. The 14-item external HCQ instrument seems to represent a unidimensional construct, and the corrected item total correlations indicate that the items can be summed to a total score [18]. Correlations with relevant variables are in line with predefined hypotheses (Table 3) and support the construct validity of the external HCQ instrument.
To the best of our knowledge, analysis of homogeneity or factor analysis have not previously been done regarding the external HCQ instrument. Our results show that two items (Table 2) are not sufficiently correlated to the other items in the instrument, which motivated their removal. This resulted in corrected item total values above the recommended value [18] for all items. However, the percentages of the variance explained by the factor models are low, indicating that the instrument does not capture the complex concept of the external housing-related control beliefs in its entirety. It could also indicate that some questions are not optimally formulated, which is a consideration further supported by the tendency to limited response distribution for some items. That is, some expressions used may not be optimal to capture true variation. Yet, the analysis of structural validity is an important step forward to increase the understanding of the concept of housing-related control beliefs. It is challenging to capture such a complex concept in its entirety when using data collection instruments.

As to internal consistency reliability, Cronbach's alpha $(\alpha=0.78)$ is acceptable in this study [18] and slightly higher than in general populations of older people $[1,2]$. This value remained unchanged in the 14-item version, supporting the use of the external HCQ instrument in the PD population. The measurement error of the external HCQ instrument has not previously been reported, and this new knowledge is important for longitudinal studies on home and health dynamics and studies of effects of housing interventions, etc. The SEM results are just below 5 points, which is a value that should be exceeded to indicate a real change [18]. It should be noted that this does not certify that a 5-point change is of clinical relevance. SEM can be influenced by different factors, such as the number of items, missing responses and vague instructions [35].

Table 3 Hypotheses and results of the correlations between external HCQ instrument and differences in Parkinson's disease severity, accessibility problems, dependence in ADL and general self-efficacy, $N=245$

\begin{tabular}{|c|c|c|}
\hline Hypotheses & Statistical result & $\begin{array}{l}\text { Hypothesis } \\
\text { confirmed }\end{array}$ \\
\hline External $\mathrm{HCQ}^{\mathrm{a}}$ expected to be significantly lower for $\mathrm{HY} \mathrm{b}^{\mathrm{b}} \mathrm{I}-\mathrm{III}$, than $\mathrm{HY} \mathrm{IV}-\mathrm{V}$ & $\begin{array}{l}\text { Median HCQ: } \\
\text { HY I-III }=37.0, \mathrm{HY} \\
\quad \mathrm{IV}-\mathrm{V}=47.5, p<0.001\end{array}$ & Yes \\
\hline $\begin{array}{l}\text { Higher external HCQ expected to significantly correlate with living with more accessibility problems }{ }^{\mathrm{c}} \\
\left(r_{\mathrm{s}>}>.37^{\mathrm{d}}\right)\end{array}$ & $r_{\mathrm{s}} 0.48, p<0.001$ & Yes \\
\hline Higher external HCQ expected to significantly correlate with being dependent in $\mathrm{ADL}^{\mathrm{e}}\left(r_{\mathrm{s}}>0.26\right)$ & $r_{\mathrm{s}} 0.41, p<0.001$ & Yes \\
\hline Higher external HCQ expected to significantly correlate with lower general self-efficacy ${ }^{\mathrm{f}}$ & $r_{\mathrm{s}}-0.35, p<0.01$ & Yes \\
\hline
\end{tabular}

${ }^{a}$ Housing-Related Control Belief Questionnaire

${ }^{\mathrm{b}}$ Hoehn and Yahr

${ }^{c}$ Housing Enabler

${ }^{\mathrm{d}}$ Spearman's correlation coefficient

${ }^{\mathrm{e}}$ Activities of daily living

${ }^{\mathrm{f}}$ General Self-Efficacy Scale 
The results of this study are congruent with previous findings showing associations between the external HCQ instrument and with ADL, life satisfaction, depression and psychological well-being [1, 9-11]. As to convergent validity, our results are in agreement with the predefined hypothesis. The correlations with accessibility problems and dependence in ADL are slightly stronger than in previous studies [1]. Although theoretically, housing is only one of several specific domains of the concept of control beliefs [36]. The wider concept general control beliefs is a good predictor of quality of life, but not to predict how people cope with challenges in specific domains [37]. Research shows that with age the control over work, finances and marriage tends to increase, whereas control decreases in relation to relationships with children and sex life [36]. The fact that no recent studies have addressed these associations highlights the need for further research on these intriguing relationships.

In the PD population, research on housing has typically addressed interventions such as home modifications [38], while there a few studies aiming to increase the knowledge about how environmental aspects are associated with health. Few studies have focused on home and health dynamics in a comprehensive manner, and to deepen the knowledge about person-environment relationships the diversity of housing aspects warrants more research attention. To the best of our knowledge, the external HCQ instrument has only been used in two studies $[16,17]$. Results from such studies give important information on housing aspects and associations to independence and autonomy [6], which is useful for rehabilitation and development of housing interventions and policies.

\section{Study limitations}

The external HCQ instrument was developed as an unpublished German version and first assessed in the Interdisciplinary Longitudinal Study on Adult Development [39]. Later, it was translated to English [4] and Swedish [3]. We used the Swedish version but then used the English version for presentation in this paper. Overall, translations of instruments into different languages are challenging and might result in differences regarding psychometric properties. Although back translation often is considered the golden standard for instrument translation processes, its value or utility has been questioned. Back translation is not free from error and does not necessarily give a clear indication of the quality of a forward translation [40] Thus, Oswald et al. [3] engaged a multi lingual research team in an iterative translation process, which resulted in a Swedish version of the HCQ instrument of good quality. However, we cannot rule out that translation aspects underlie some of the differences in relation to previous studies evaluating the instrument.
Further, the percentages of the variance explained by the factor models are low, indicating that the instrument does not capture the complex concept of the external housingrelated control beliefs in its entirety. This could also indicate that some questions are not optimally phrased, which is a consideration further supported by the tendency to limited response distribution for some items. In other words, some expressions used may not be optimal to capture true variation.

It is important to use psychometrically sound instruments in both research and practice [35]. However, a psychometric evaluation is an on-going progress and additional studies are warranted. A limitation in this study is that test-retest reliability was not possible to evaluate, because the HHPD project was not designed to evaluate test-retest reliability. Thus, the database did not include the data required for such evaluation. Accordingly, that kind of analysis was not feasible within the HHPD project. To compare test-retest values would have been interesting, as Oswald et al. showed high to medium results for the original external HCQ sub-scales [3].

\section{Conclusions}

This study indicates that the reliability and construct validity of the external HCQ instrument is sufficient, and supports the use of the 14-item version in the PD population. The structural validity of the instrument is not optimal due to the low explanation of the variance of the complex concept of housing-related control beliefs. Although, external HCQ instrument seems to represent a unidimensional construct, which is meaningfully related to relevant variables. The results pave the way for further psychometric studies, as well as studies on how perceptions of external control of the home are associated with different aspects of health among people with PD. The HCQ instrument is foremost useful in research to further the understanding of housing and health dynamics in different sub-groups of the ageing population, for example, people with PD. Such knowledge has the potential to support the development of rehabilitation services, housing interventions and policies supporting active and healthy ageing in this specific population.

Acknowledgements Open access funding provided by Lund University. We thank the persons who volunteered to participate and to statistician, Ph.D. S. Ullén for valuable analysis and interpretation of the results. The HHPD project was funded by the Strategic Research Area in neuroscience (MultiPark) at Lund University, the Swedish Research Council, the Ribbingska Foundation in Lund, the Greta and Johan Kock Foundation, the Swedish Association of Persons with Neurological Disabilities (NHR), the Swedish Parkinson Foundation, the NorrbackaEugenia Foundation, NEURO Sweden, and the Crafoord Foundation. This study was conducted within the context of the Centre for Ageing and Supportive Environments (CASE) at Lund University. The first 
author's learning process was supported by the Swedish National Graduate School for Competitive Science on Ageing and Health (SWEAH), financed by Swedish Research Council.

Data availability The dataset for the current study is not publicly available due to ongoing longitudinal data collections. The data is stored at the Health Science Centre (Lund University, Sweden) and can be requested from Maria H. Nilsson (Principal Investigator; maria_h.nilsson@med.lu.se).

\section{Compliance with ethical standards}

Conflict of interest The authors declare that they have no conflict of interest.

Ethical approval All procedures performed in studies involving human participants were in accordance with the ethical standards of the Regional Ethical Review Board in Lund approved the HHPD (No. 2012/558) and with the 1964 Helsinki declaration and its later amendments or comparable ethical standards.

Informed consent All participants provided written informed consent.

Open Access This article is licensed under a Creative Commons Attribution 4.0 International License, which permits use, sharing, adaptation, distribution and reproduction in any medium or format, as long as you give appropriate credit to the original author(s) and the source, provide a link to the Creative Commons licence, and indicate if changes were made. The images or other third party material in this article are included in the article's Creative Commons licence, unless indicated otherwise in a credit line to the material. If material is not included in the article's Creative Commons licence and your intended use is not permitted by statutory regulation or exceeds the permitted use, you will need to obtain permission directly from the copyright holder. To view a copy of this licence, visit http://creativecommons.org/licenses/by/4.0/.

\section{References}

1. Oswald F, Wahl HW, Schilling O et al (2007) Housing-related control beliefs and independence in activities of daily living. Scand J Occup Therap 14:33-43. https://doi.org/10.1080/11038 120601151615

2. Oswald F, Kaspar R (2012) On the quantitative assessment on perceived housing in later life. J Hous Elderly 26:72-93. https:// doi.org/10.1080/02763893.2012.673391

3. Oswald F, Schilling O, Wahl HW et al (2006) Homeward bound: introducing a four-domain model of perceived housing in very old age. J Environ Psychol 26:187-201. https://doi.org/10.1016/j. jenvp.2006.07.002

4. Oswald F, Wahl HW, Martin M et al (2003) Towards measuring proactivity in person-environment transactions in late adulthood: the Housing-Related Control Beliefs Questionnaire. J Hous Elderly 17:135-152. https://doi.org/10.1300/J081v17n01_10

5. Leith KH (2006) "Home is where the heart is..or is it?" A phenomenological exploration of the meaning of home for older women in congregate housing. J Aging Stud 20:317-333. https:// doi.org/10.1016/j.jaging.2005.12.002

6. Reich JW, Zatura AJ (1990) Dispositional control beliefs and the consequence of control-enhancing intervention. J Gerontol Psychol Sci 45:46-51
7. Strickland B (1978) Internal-external expectancy and healthrelated behaviours. J Consult Clin Psychol 46:1192-1211

8. Heckhausen J, Schulz R (1995) A life-span theory of control. Psychol Rev 102:284-304. https://doi. org/10.1037/0033-295x.102.2.284

9. Kylén M, Schmidt SM, Iwarsson S et al (2017) Perceived home is associated with psychological well-being in a cohort aged $67-70$ years. J Environ Psychol 51:239-247. https://doi.org/10.1016/j. jenvp.2017.04.006

10. Wahl HW, Schilling O, Oswald F, Iwarsson S (2009) The home environment and quality of life-related outcomes in advance age: findings of the ENABLE-AGE project. Eur J Ageing 6:101-111. https://doi.org/10.1007/s10433-009-0114-z

11. Tomsone S, Horstman V, Oswald F et al (2013) Aspects of housing and perceived health among ADL dependent groups of older people in three national samples. Ageing Clin Exp Res 25:317-328. https://doi.org/10.1007/s40520-013-0050-9

12. Vossius C, Nilsen OB, Larsen JP (2009) Parkinson's disease and nursing home placement: the economic impact of the need for care. Eur J Neurol 16:194-200. https://doi.org/10.111 1/j.1468-1331.2008.02380.x

13. Hairz GM, Forsgren L (2011) Activities of daily living and quality of life in persons with newly diagnosed Parkinson's disease according to subtypes of disease, and in comparison to healthy controls. Acta Neurol Scand 123:20-27. https://doi.org /10.1111/j.1600-0404.2010.103144.x

14. Sjödahl Hammarlund C, Westergren A, Åström I et al (2018) The impact of living with Parkinson's disease: balancing within a web of needs and demands. Parkinson's Dis. https://doi. org/10.1155/2018/4598651

15. Hely M, Morris J, Traficante R et al (1999) The Sydney multicentre study of Parkinson's disease: progression and mortality at 10 years. J Neurol Neurosurg Psychiatry 67:300-307

16. Nilsson MH, Haak M, Iwarsson S (2013) Housing and health: Very old people with self-reported Parkinson's disease versus controls. Parkinson's Dis. https://doi.org/10.1155/2013/710839

17. Nilsson MH, Ullén S, Ekström H et al (2016) The association between indicators of health and housing in people with Parkinson's disease. Geriatrics 16:146-154. https://doi. org/10.1155/2013/710839

18. Hobart J, Cano S (2009) Improving the evaluation of therapeutic interventions in multiple sclerosis: the role of new psychometric methods. Health Technol Assess 13:1-177. https://doi. org/10.3310/hta13120

19. Nilsson MH, Iwarsson S (2013) Home and health in people ageing with Parkinson's disease: study protocol for a prospective longitudinal cohort survey study. BMC Neurol 13:142-150. https://doi.org/10.1186/1471-2377-13-142

20. Nasreddine ZS, Phillips NA, Bédirian V et al (2005) The Montreal Cognitive Assessment, MoCA: a brief screening tool for mild cognitive impairment. J Am Geriatr Soc 53:695-699. https ://doi.org/10.1111/j.1532-5415.2005.53221.x

21. Ramaker C, Marinus J, Stiggelbout AM et al (2002) Systematic evaluation of rating scales for impairment and disability in Parkinson's disease. Mov Disord 17:867-876. https://doi. org/10.1002/mds. 10248

22. Rosqvist K, Hagell P, Odin P et al (2017) Factors associated with life satisfaction in Parkinson's disease. Acta Neurol Scand 136:64-71. https://doi.org/10.1111/ane.12695

23. Hoehn MM, Yahr MD (1967) Parkinsonism: onset, progression and mortality. Neurology 17:427-442. https://doi.org/10.1212/ WNL.17.5.427

24. Iwarsson S, Slaug B (2010) Housing enabler-a method for rating/screening and analysing accessibility problems in housing. Manual for the complete instrument and screening tool, 2nd edn. Veten \& Skapen HB \& Slaug Data Management, Lund 
25. Åsberg KH, Sonn U (1989) The cumulative structure of personal and instrumental ADL. A study of elderly people in a health service district. Scand J Rehab Med 21:171-177

26. Sonn U, Åsberg KH (1991) Assessment of activities of daily living in elderly. A study of a population of 76-year-olds in Gothenburg, Sweden. Scand J Rehab Med 23:193-202

27. Iwarsson A, Horstmann V, Sonn U (2007) Housing matters in very old age yet differently due to dependence level differences. Scand J Occup Therap 14: 3-15. https://doi.org/10.10800/11038 120601094732

28. Schwarzer R, Jerusalem M (1995) Generalized Self efficacy scale. In: Weinman J, Wright S, Johnston M (eds) Measures in health psychology: a users portfolio. Casual and control beliefs. NER-NELSON, Windsor, pp 35-37

29. Nilsson MH, Hagell P, Iwarsson S (2015) Psychometric properties of the General Self-Efficacy Scale in Parkinson's disease. Acta Neurol Scand 132:89-96. https://doi.org/10.1111/ane.12368

30. Costello AB, Osborne JW (2005) Best practice in exploratory factor analysis: four recommendations for getting the most from your analysis. Pract Assess Res Eval 10:1-9. https://doi. org/10.4135/9781412995627.d8

31. Finch E (2002) Physical rehabilitation outcome measures, 2nd edn. Decker, Mississauga

32. Hobart JC, Riazi A, Lamping DL et al (2004) Improving the evaluation of therapeutic interventions in multiple sclerosis: development of a patient-based measure of outcome. Health Technol Assess 8:1-48

33. Akoglu H (2018) User's guide to correlation coefficients. Turk J Emerg Med 18:91-93. https://doi.org/10.1016/j.tjem.2018.08.001

34. Tabachnik BG, Fidell LS (2001) Using multivariate statistics. Allyn \& Bacon, Boston
35. Mayo A (2015) Psychometric instrumentation: reliability and validity of instruments used for clinical practice, evidence-based practice projects and research studies, vol 26. Nursing and Health Science Faculty Publication. https://digital.sandiego.edu/nursi ng_facpub/26

36. Lachman ME, Weaver SL (1998) Sociodemographic variations in the sense of control by domain: findings from the MacArthur studies of midlife. Psychol Aging 13:553-562

37. Lachman ME (1993) Planning and control processes across the life span: an overview. Int J Behav Dev 16:131-145

38. Bhidayasiri R, Jitkritsadakul O, Boonrod N et al (2015) What's the evidence to support home environment adaptation in Parkinson's disease? A call for multidisciplinary intervention. Parkinsonism Relat Disord 10:1127-1132. https://doi.org/10.1016/j.parkreldis .2015 .08 .025

39. Martin P, Ettrich KU, Lehr U et al (eds) (2000) Aspekte der Entwicklung im mittleren und höheren Lebensalters Ergebnisse der Interdisziplinären Längsschnittstudie des Erwachsenenalters (ILSE). [Developmental aspects in middle and late adulthood. Results from the interdisciplinary longitudinal study on adult development (ILSE).] Steinkopff, Darmstadt.

40. Sidani S, Guruge S, Miranda J et al (2010) Cultural adaptation and translations of measures: an integrated method. Res Nurs Health 33:133-143. https://doi.org/10.1002/nur.20364

Publisher's Note Springer Nature remains neutral with regard to jurisdictional claims in published maps and institutional affiliations. 